\title{
Antibiotic Therapy and Bacterial Odontogenic Infections: An Overview
}

\author{
${ }^{1}$ Georges Aoun, ${ }^{2}$ Ghassan Yared, ${ }^{3}$ Hicham A Diab, ${ }^{4}$ Antoine Berberi
}

\begin{abstract}
Odontogenic infections (Ols) are common in the oral and maxillofacial regions and can affect both genders at any age. Infection of the dental pulp resulting from caries and their major pathogens, the streptococci, is the most important cause of Ols. In fact, following bacterial attack, the dental pulp becomes necrotic and the bacteria of the normal flora undergo a change from main aerobes to anaerobes leading to an abscess formation at the apex of the root. In some cases, the infection may spread to the surrounding spaces resulting in additional complications. Hence, their early diagnosis and adequate therapy are requisite.

Successfully treating Ols depends from one side on eliminating the causal factor and from the other side selecting the appropriate anti-infectious agent. This selection should be considered according to each and every clinical case based on clinical and bacteriological factors, with the use of broadspectrum antibiotics for short periods of time.

This article aims to set out the most common odontogenic infectious diseases as well as the involved germs and to help dentists choosing the right antibiotic.
\end{abstract}

Keywords: Antibiotic, Bacteria, Infection, Odontogenic.

How to cite this article: Aoun G, Yared G, Diab HA, Berberi A. Antibiotic Therapy and Bacterial Odontogenic Infections: An Overview. World J Dent 2018;9(2):154-161.

Source of support: Nil

Conflict of interest: None

\section{INTRODUCTION}

Odontogenic infections are relatively frequent and can affect all ages. Generally, their management requires an antibiotic therapy (AT), which should not, in any way, replace the main clinical treatment consisting of drainage

\footnotetext{
${ }^{1}$ Department of Oral Medicine and Maxillofacial Radiology Faculty of Dental Medicine, Lebanese University, Beirut Lebanon

${ }^{2}$ Department of Diagnosis and Oral Medicine, Faculty of Dental Medicine, Saint Joseph University, Beirut, Lebanon

${ }^{3}$ Department of Pediatric and Community Dentistry, Faculty of Dental Medicine, Lebanese University, Beirut, Lebanon

${ }^{4}$ Department of Oral and Maxillofacial Surgery, Faculty of Dental Medicine, Lebanese University, Beirut, Lebanon

Corresponding Author: Georges Aoun, Department of Oral Medicine and Maxillofacial Radiology, Faculty of Dental Medicine, Lebanese University, Beirut, Lebanon, e-mail: aoungeorges@yahoo.com
}

of the infection by all conceivable means (incision, packing, curettage, tooth trepanation, extraction, etc.). ${ }^{1-4}$

Although AT is essential in some cases, it is often used improperly. In fact, the literature reports lack of knowledge among dentists regarding the choice of adequate antibiotic and/or the clinical situations indicated for AT.

When required, the prescription of an antibiotic should be the result of a comprehensive evaluation that takes into consideration the patient's general and oral health, the causative bacterial agent, and the properties of the drug (range of activities, capacity of diffusion, etc.). ${ }^{1-4}$

The aim of this article is to highlight these facts and to give the information needed for a more suitable and efficient AT facing the most frequent OIs.

\section{NORMAL ORAL MICROFLORA}

Oral microbiota is characterized by a great number of microorganisms, among which bacteria whose nature (Gram-positive or Gram-negative), ecology (aerobes, anaerobes, etc.), and morphology (cocci, rods, etc.) are extremely variable ${ }^{5}$ (Table 1 ).

These bacteria find in the oral cavity the necessary conditions for growing since it has an average temperature of $35^{\circ} \mathrm{C}$ to $37^{\circ} \mathrm{C}$, it is well humidified, widely supplied with nutritive materials and it shows, depending on the sites, different pressures of oxygen. ${ }^{5-7}$

In the oral cavity, this microflora can largely differ depending on anatomical sites. The microbial population existing on teeth surface is different from that of the gingival sulcus, which, in turn, is also different from the one found on the tongue or on the oral mucosa. ${ }^{7,8}$

Moreover, the diversity of these populations depends on other factors, such as age, nutritional diet, the presence of healthy or decayed teeth and or periodontal diseases, personal oral hygiene, smoking, AT, hospitalization, pregnancy, as well as hereditary and racial factors. ${ }^{5,8,9}$ The oral environment composed of a set of structures, and more locally of gingival fluid, shows physicochemical and nutritional conditions favorable to the emergence and development of a very diverse commensal bacterial flora. ${ }^{5,9}$

In normal physiological conditions, the microbiota is stable and is clinically expressed by a good oral health. 5,6,9 However, any general disorder (anemia, immune deficiency) and/or a local one (poor oral hygiene, smoking) 
Antibiotic Therapy and Bacterial Odontogenic Infections

Table 1: Principal bacterial species found in the oral cavity according to Marsh and Martin

\begin{tabular}{llll}
\hline Cocci Gram-positive & Rods Gram-positive & Cocci Gram-negative & Rods Gram-negative \\
\hline Abiotrophia & Actinobaculum & Anaeroglobus & Aggregatibacter \\
Enterococcus & Actinomyces & Mega sphaera & Campylobacter \\
Finegoldia & Alloscardovia & Moraxella & Cantonella \\
Granulicatella & Arcanobacterium & Neisseria & Capnocytophaga \\
Peptostreptococcus & Atopobium & Veillonella & Centipeda \\
Streptococcus & Bifidobacterium & & Desulfomicrobium \\
Gemella & Corynebacterium & Desulfovibrio \\
& Eubacterium & Dialister \\
& Filifactor & Eikenella \\
& Lactobacilus & Flavobacterium \\
& Mogibacterium & Fusobacterium \\
& Olsenella & Haemophilus \\
& Parascardovia & Johnsonii \\
& Propionibacterium & Kingella \\
& Pseudoramibacter & Porphyromonas \\
& Rothia & Prevotella \\
& Scardovia & Treponema \\
\hline
\end{tabular}

might lead to a qualitative and quantitative distortion of this bacterial balance and the possible appearance of infectious troubles. ${ }^{5-9}$

\section{ANTIBIOTICS}

An antibiotic is a drug that can either induce bacterial death (bactericidal effect) or inhibit bacterial growth (bacteriostatic effect). ${ }^{1,3}$

In serious infections, a synergistic association of antibiotics can be used to enlarge the spectrum. It is especially useful in cases in which the causative bacteria are unknown, when the infection requires stronger action, and to control the progression of resistant. ${ }^{1,3,4}$

Nevertheless, such combination may result in a negative, antagonistic interaction in some cases. Specifically, the combination of bacteriostatic and bactericidal antibiotics is antagonistic generally. In addition, care should be taken to avoid associating more than two antibiotics belonging to the same family or having similar toxicity. ${ }^{1,3}$

\section{THE AT RELATED TO EIGHT FREQUENT Ols}

In clinical practice, some fundamental notions should be respected in front of any infection ${ }^{1,3,4}$ :

- Drainage of the infection and elimination of the causal factor

- Evaluation of the general health of the patient which often depends on the AT protocol

- Starting the AT while keeping in mind the antibiotic dosage depending on the patient's age and risk of allergy.

In order for the AT to succeed, two things must be done: (1) accurately define the nature of bacteria responsible for the infection; a bacteriological study and an antibiogram are indicated in the severe cases and (2) evaluate the dosage (g/day or MU/day), the posology (times/day), and the duration of the treatment based on the pharmacodynamics and pharmacokinetics of each molecule. . $^{1,3,4}$

\section{Root Canal Infection}

Root canal infection is the consequence of microorganisms' colonization leading to pulpal necrosis; it generally results from deep dental caries or tooth filling, trauma, or unsuccessful root canal treatment. ${ }^{10,11}$

In this infection, anaerobes and Gram-positive bacteria like Peptostreptococcus and Streptococcus spp. are the mostly found, followed by black-pigmented bacteria including Prevotella and Porphyromonas spp. ${ }^{11,12}$ (Table 2).

This clinical entity was often underestimated in terms of morbidity and mortality; however, if neglected, bacteria are capable of entering the periapical tissues through the apical foramen, hence inducing an acute inflammation leading to pus formation. ${ }^{10}$

Table 2: Distribution of bacterial species frequently present in necrotic pulps according to Gajan et al ${ }^{11}$

\begin{tabular}{ll}
\hline Species & Prevalence (\%) \\
\hline Peptostreptococcus & 16 \\
Streptococcus & 14.2 \\
Porphyromonas & 12.2 \\
Enterococcus faecalis & 9.6 \\
Staphylococcus salivarius & 8.6 \\
Prevotella spp. & 8.1 \\
Lactobacillus spp. & 7.1 \\
Actinomyces spp. & 7.1 \\
Veillonella spp. & 2.5 \\
Eubacterium spp. & 2.5 \\
Bacillus spp. & 2 \\
Escherichia coli & 1.6 \\
\hline
\end{tabular}


The infection may then quickly progress and spread to contiguous anatomic structures, leading to severe complications. ${ }^{13}$

The treatment of this condition suggests the total elimination of bacteria from the root canal by an adequate canal preparation followed by a hermetic canal obturation. ${ }^{14}$

Nevertheless, in some cases, AT consisting of betalactam agents, such as amoxicillin can make clinical improvement. It is to be noted that, in dentistry, most practitioners prescribe beta-lactams (agents containing a beta-lactam ring in their molecular structures) for their broad-spectrum activity; however, bacteria frequently counteract these beta-lactam agents by producing a betalactamase enzyme capable of attacking the beta-lactam ring. To overcome this resistance, the clavulanic acid which is a beta-lactamase inhibitor was added to beta lactam-antibiotic (amoxicillin).

If the patient is known to be allergic to beta-lactams, macrolides (spiramycin, erythromycin, etc.) are to be used. $^{13,14}$

\section{Periapical Infection}

Periapical infection also known as dental abscess or dentoalveolar abscess is a clinical entity used to describe a collection of pus located in the alveolar bone; it appears radiologically as a well-defined radiolucent image connected to the root apex of the infected tooth ${ }^{10}$ (Fig. 1).

In this infection, the infiltration starts from the bacterial plaque and or the saliva through the pulp chamber and diffuse into the alveolar bone. ${ }^{15,16}$

Bacteria concerned in the progression of this type of infection include mostly a complex mix of facultative and obligate anaerobes. ${ }^{17}$

Among obligate anaerobes, Bacteroides spp., Peptostreptococcus spp., Peptococcus spp., and Fusobacterium spp., are the most isolated. As for facultative anaerobes, the most prevalent bacteria belong to Staphylococcus spp. and Streptococcus spp. ${ }^{17}$

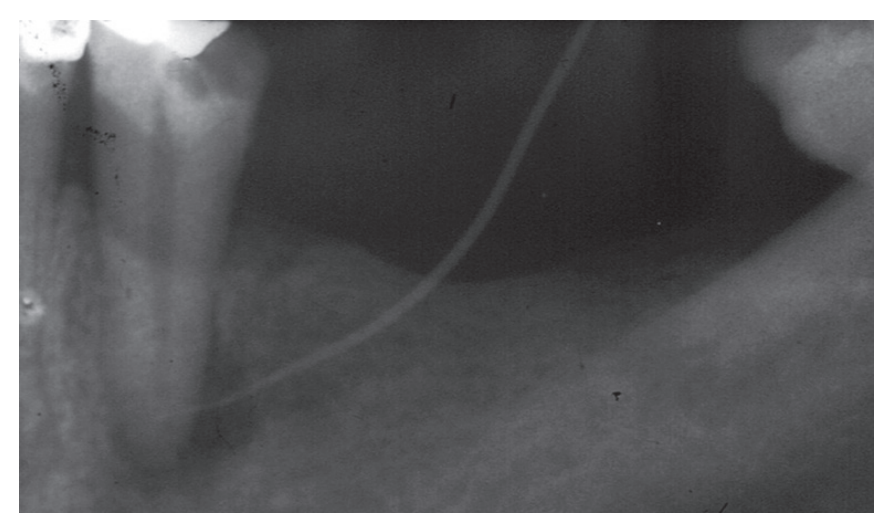

Fig. 1: X-ray showing a radiolucent image related to the apex of root of a mandibular premolar; a gutta-percha cone was introduced through the path of the fistula
To manage this condition, AT that must never replace the appropriate drainage and/or debridement must be started the earliest in order to shorten the period of infection and minimize the risk of bacteremia. ${ }^{13}$ In severe cases, antibiotics association is recommended. ${ }^{14,15}$

The association of amoxicillin-clavulanic acid with a dosage of $1 \mathrm{gm}$ twice a day is considered the AT of choice. ${ }^{18-20}$

\section{Maxillofacial Cellulitis}

Cellulitis is an infection of the subcutaneous tissue generally related to dental pathology as a complication of the periapical infection. ${ }^{15,21}$

Clinically, a spreading erythema, warmth, tenderness, and swelling are apparent (Figs 2A to C); the patient feels severe and diffuse discomfort. The radiological examination highlights a radiolucent image in regard to the causal tooth. ${ }^{16,22}$ (Fig. 2D).

In this type of infection, a polymicrobial association of anaerobes and aerobes in a proportion of 65 and 35\% respectively, is isolated; commonly, these are anaerobic cocci, Gram-positive Streptococcus milleri group, Peptostreptococcus, and anaerobic Gram-negative rods, such as Bacteroides (Prevotella). ${ }^{23}$

Anaerobic Gram-negative cocci and anaerobic Grampositive rods are rare. ${ }^{23}$

Fusobacterium nucleatum is found in severe infections where the microbiological examination and an antibiogram are indicated. ${ }^{5,24}$ The clinical signs of a severe infection may include fever (temperature $>38^{\circ} \mathrm{C}$ ), stridor, painful swallowing, etc. ${ }^{25}$

The treatment of a diagnosed maxillofacial cellulitis includes management of the source of infection and prescription of appropriate antibiotics; the patient's diet status should be addressed, as many of them in similar situation decrease oral intake due to pain and difficulty in chewing or swallowing. ${ }^{22}$

As for the AT, the clinician must prescribe the narrowest spectrum of antibiotics capable of covering all possible bacteria for a period of 7 days or until 3 days after symptoms have resolved. ${ }^{22}$

High dose of an association of amoxicillin and clavulanic acid has been effective, and powerfully avoids resistance. $^{26}$

\section{Cervicofacial Actinomycosis}

Actinomycosis is an uncommon chronic disease caused by anaerobic Gram-positive bacteria (Actinomyces spp.) that usually colonize the oropharynx, the digestive, and the genital tracts. ${ }^{27}$ Cervicofacial actinomycosis following a dental infection is the most frequent among all the forms of actinomycosis and represents $60 \%$ of all reported cases. ${ }^{28}$ 


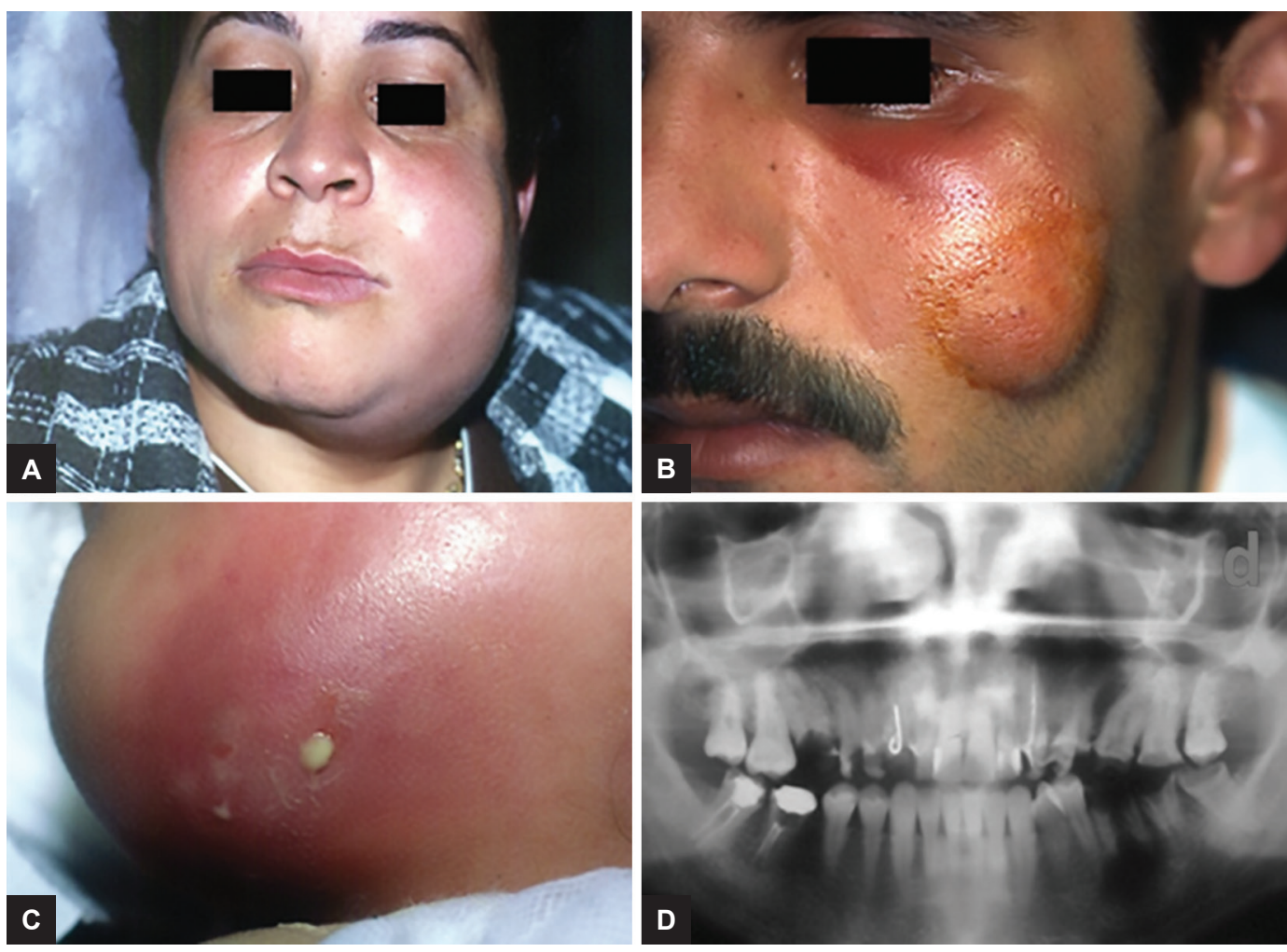

Figs 2A to D: (A) Severe cellulitis located in the mandible region. (B) Cellulitis located in the maxilla region. (C) Suppurative cellulitis with an extraoral drainage of the pus located in the mandible/mental region.

(D) Panoramic X-ray showing a radiolucent image related to the remaining roots of tooth \#36

Clinically, this condition is characterized by contiguous spread; suppurative and granulomatous inflammation presents as a chronic, painless indurated mass, evolving into multiple abscesses with draining sinus tracts on the skin surface or oral mucosa and discharging sulfur granules ${ }^{28-30}$ (Fig. 3).

At later phases, pain and trismus may occur, related to the infiltration of the masticatory muscles. ${ }^{27}$

The histological examination and bacterial culture are the cornerstones of cervicofacial actinomycosis diagnosis. ${ }^{27}$

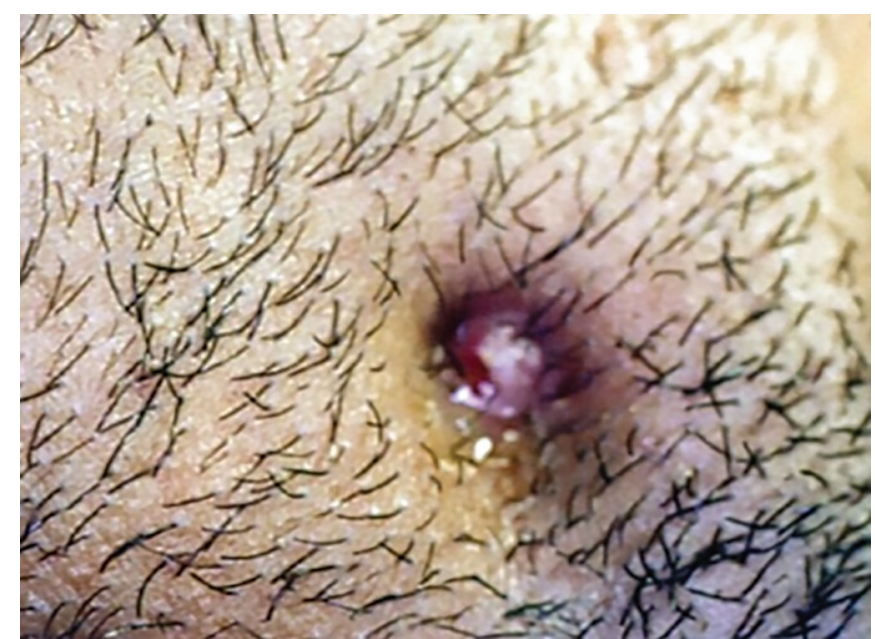

Fig. 3: Facial actinomycosis
In $70 \%$ of cases, Actinomyces israelii and Actinomyces gerencseriae are the most frequent followed by many other species like Actinomyces meyeri, Actinomyces odontolyticus, Actinomyces naeslundii, Actinomyces georgiae, Actinomyces pyogenes, and Actinomyces viscosus. ${ }^{31}$

In cervicofacial actinomycosis, AT is required; it must be at high doses of penicillin $\mathrm{G}$ or amoxicillin-clavulanic acid (the pathogens are susceptible to beta-lactams) and prolonged (because the penetration of beta-lactams in bone is low) between 2 and 12 months.

In patients in whom surgical resection of the infected tissue is carried out, the AT may be reduced to 3 months, ${ }^{27,32}$ Moghimi et al ${ }^{32}$ recommend a surgical approach with a daily intravenous mixture of 12 million units of penicillin $\mathrm{G}$ and $1500 \mathrm{mg}$ of metronidazole (500 mg 3/day) until clinical improvement followed by oral antibiotics for 2 to 4 weeks.

\section{Alveolar Osteitis and Osteomyelitis of the Jaws}

Alveolar osteitis or dry socket is a severely painful complication that may occur 3 to 4 days after a tooth extraction; it is characterized by a localized fibrinolysis leading to a partial or total disintegration of the blood clot within the alveolar socket ${ }^{33,34}$ (Fig. 4).

The prevalence of alveolar osteitis is around 3\% for all extractions and can reach over 30\% for impacted mandibular third molars. ${ }^{35}$ 


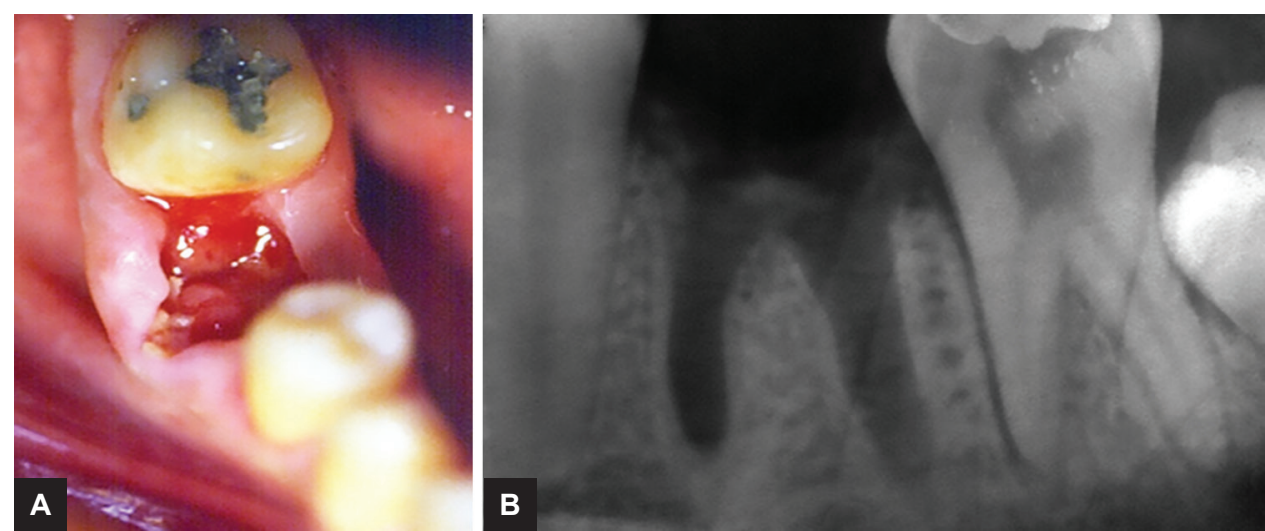

Figs 4A and B: (A) Alveolitis post extraction of a first mandibular molar. (B) Intraoral radiograph of the case in " $4 \mathrm{~A}$ "

In the case of dry alveolitis, AT is not necessary; ${ }^{36}$ however, it is indicated in case of suppurative alveolitis where the responsible germs are Prevotella, Fusobacterium, Staphylococcus aureus, and Streptococcus pyogenes. 5,6

The first-choice antibiotic remains amoxicillin and in case of allergy to beta-lactams, macrolides can be used. ${ }^{36}$

As for osteomyelitis, it is defined as an inflammation of the medullary bone within the maxilla or mandible with possible extension into the adjacent cortical bone and the overlying periosteum. This condition may be acute or chronic and can be extremely difficult to treat. ${ }^{5,6}$

In recent years, osteomyelitis has been observed in patients taking bisphosphonates for the treatment of osteoporosis or breast cancer. ${ }^{5}$

Treatment is based on local debridement and topical antiseptic on exposed areas. Clindamycin is a recommended antibiotic due to its ability to achieve therapeutic levels within the bone. In some severe cases, osteomyelitis requires hospitalization and an additive treatment other than antibiotics like hyperbaric oxygen therapy. ${ }^{37} \mathrm{Chronic}$ osteomyelitis of the jaws is common in the developing countries, where these diseases are associated with trauma, surgical procedures, and previous infections, such as endodontic and periapical infections. ${ }^{37}$

As the majority of osteomyelitis cases begin as dentoalveolar abscess, they share the same microbiota. However, it is possible that pathogens different from those of the oral microbiota may reach the bone tissues through transient bacteremia, which are common after surgical procedures or traumas; ${ }^{38}$ among bacteria implicated in the chronic type of osteomyelitis are Staphylococcus aureus (in $90 \%$ of cases), Staphylococcus epidermidis, Pseudomonas aeruginosa, Serratia marcescens. Escherichia coli are also isolated in cases of chronic osteomyelitis. 5,6

In the chronic osteomyelitis associated with previous OIs, the microbiota added to the above-cited bacteria can then comprise Tannerella, Prevotella, Porphyromonas, Fusobacterium, Parvimonas, Actinomycetes, and Staphylococci. ${ }^{6}$

\section{Odontogenic Sinusitis}

A periapical infection derived from a dental infection can occasionally reach the maxillary sinus causing odontogenic sinusitis, ${ }^{39}$ this can be due to the proximity of the maxillary posterior teeth roots to the sinus floor. ${ }^{5,6}$

Other causes of odontogenic sinusitis include periodontitis, perforation of the Schneiderian membrane of the sinus during extraction or surgery, the presence of root tips, or other foreign bodies, such as endodontic obturation materials in the sinus. ${ }^{40,41}$

According to Puglisi et $\mathrm{al}^{42} 15$ types of aerobes and 25 of anaerobes bacteria were isolated from patients with odontogenic sinusitis. The most common aerobes were Staphylococcus aureus and Streptococcus pneumoniae, while the most frequent anaerobes were Peptostreptococcus spp. and Prevotella spp.

Chronic odontogenic sinusitis is better diagnosed radiologically using computed tomography (CT) scanning that provides excellent detail of sinus anatomy (Fig. 5).

Typical treatment of odontogenic sinusitis includes an adequate treatment of the infection etiology (root canal

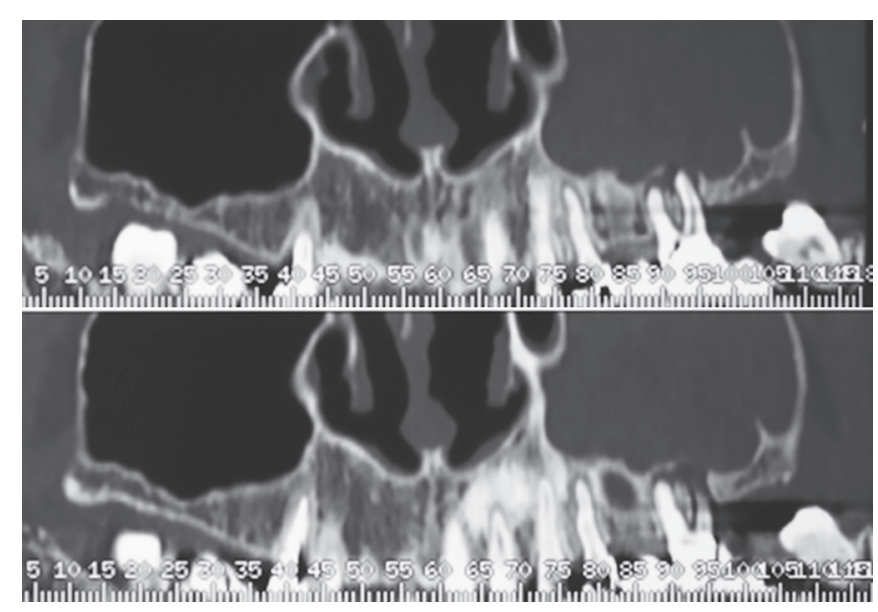

Fig. 5: Panoramic reconstruction of CT showing the complete opacification of the maxillary sinus (sinusitis related to the tooth \#26) 

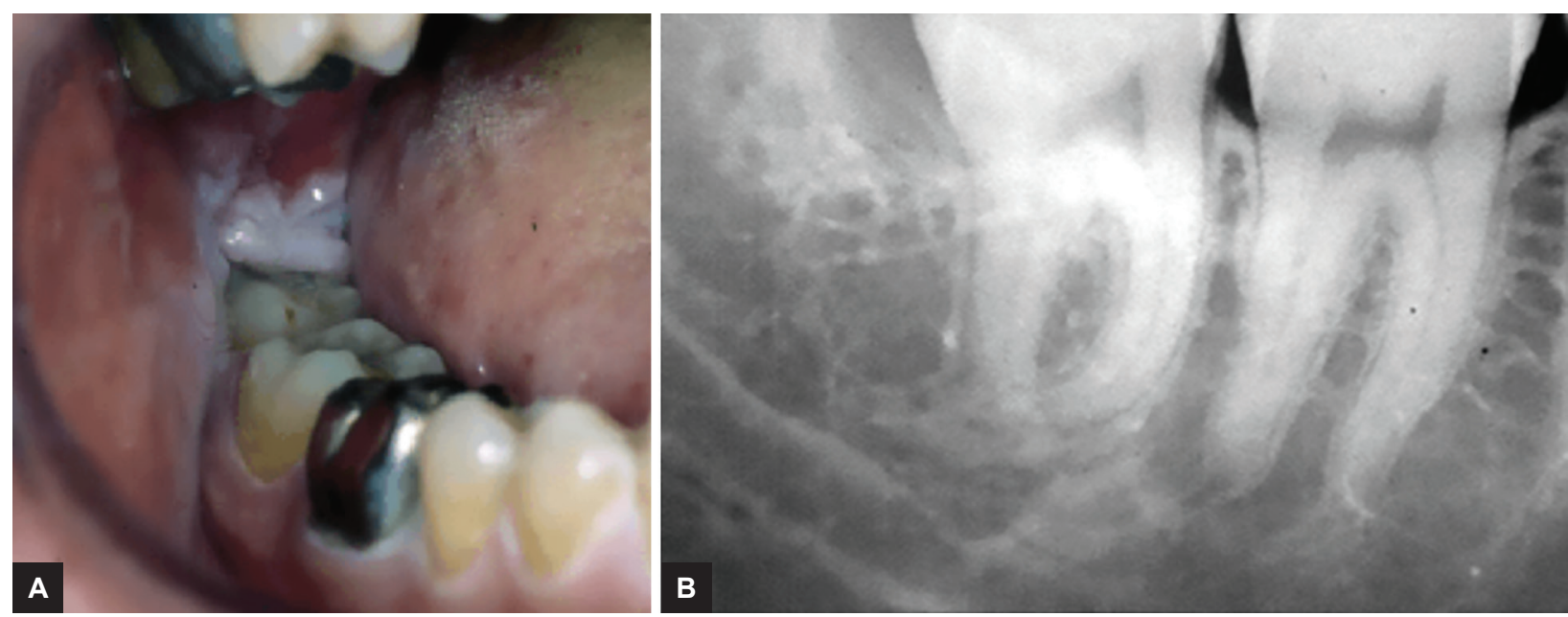

Figs 6 A and B: (A) Acute pericoronitis. (B) Intraoral radiograph of the case in " $6 \mathrm{~A}$ "

treatment, surgical extraction, etc.) accompanied by a 3- to 4-week trial of AT with adequate oral and sinus flora coverage; association of amoxicillin and clavulanic acid is indicated, and in case of allergy to beta-lactams, macrolides are used.

\section{Pericoronitis}

Pericoronitis is an inflammation of the soft tissues around the crown of a partially erupted tooth usually the third molar; it is painful particularly when the opposing tooth causes additional trauma on the inflamed tissues ${ }^{5,6}$ (Fig. 6).

This condition is due to an infection in the space between the tooth and overlying soft tissue. ${ }^{5}$ Obligate anaerobes, in particular Prevotella intermedia, anaerobic Streptococci, and Fusobacterium spp., are often present; recently, Aggregatibacter (formerly Actinobacillus), actinomycetemcomitans and Tannerella forsythia have been isolated also. ${ }^{15,16,43}$

Antibiotic therapy in case of a pericoronitis consists of beta-lactams (amoxicillin) and must accompany local treatment, such as rinsing and elimination of trauma caused by the antagonist tooth.

\section{Peri-implantitis}

Peri-implantitis refers to the general category of pathological changes that can occur in the hard and soft tissues surrounding an implant. The radiological examination shows a radiolucent image in relation with one or several parts of the implant ${ }^{5,6}$ (Fig. 7).

The stability of the osseointegration of an implant can be jeopardized by the presence of inflammatory changes that cause loss of the supportive bone. ${ }^{44}$

Most cases of peri-implantitis are induced by bacterial species including Aggregatibacter actinomycetemcomitans, Campylobacter gracilis, Campylobacter rectus, Campylobacter showae, Helicobacter pylori, Haemophilus influenzae,

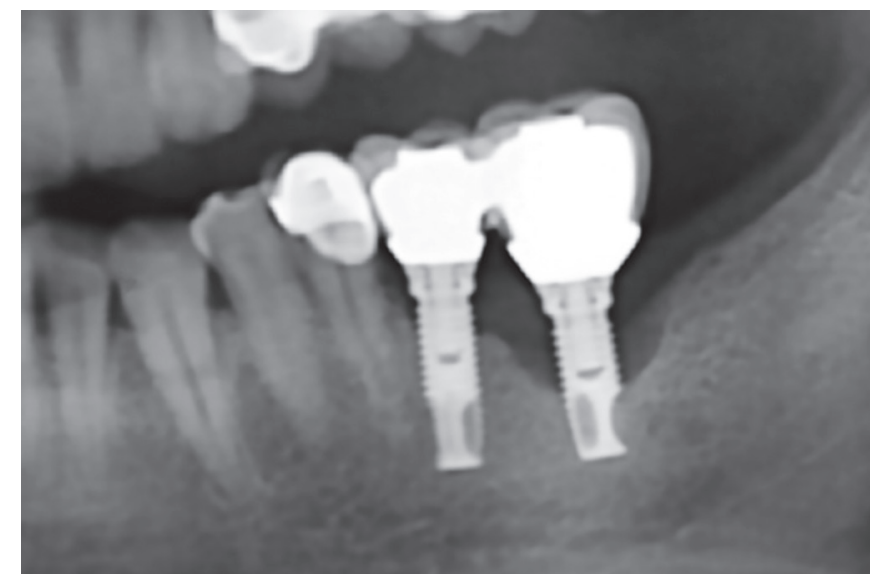

Fig. 7: X-ray showing important bone loss around the implants

Porphyromonas gingivalis, Staphylococcus aureus, Staphylococcus anaerobius, Streptococcus intermedius, Streptococcus mitis, Tannerella forsythia, Treponema denticola, and Treponema socranskii. ${ }^{4}$

Peri-implantitis has been shown to respond to local mechanical and chemical means of reducing the microflora in the immediate surrounding area of the implant. ${ }^{46,47}$ However, consideration has to be given to the possibility of causing physical damage to the surface of the implant. Irrigation with an antiseptic, such as $0.2 \%$ chlorhexidine, has been found to be beneficial, ${ }^{44,46}$ alternatively, AT consisting of an association between amoxicillin and clavulanic acid and metronidazole.

\section{CONCLUSION}

Odontogenic infections are common in dentistry. Most of them arise from the commensal flora added to many anaerobes bacteria. They successfully respond to drainage, such as endodontic treatment, incision, or tooth extraction, but an extra AT may also be required. The antibiotic of choice is usually an association between amoxicillin and clavulanic acid which helps to overcome 
the bacterial resistance problem by its beta-lactamase inhibition properties.

\section{REFERENCES}

1. Durkin MJ, Hsueh K, Sallah YH, Feng Q, Jafarzadeh SR, Munshi KD, Lockhart PB, Thornhill MH, Henderson RR, Fraser VJ; Centers for Disease Control and Prevention Epicenters. An evaluation of dental antibiotic prescribing practices in the United States. J Am Dent Assoc 2017 Dec;148 (12):878-886.

2. GutiérrezJL, BagánJV, Bascones A, Llamas R, Llena J, Morales A, Noguerol B, Planells P, Prieto J, Salmerón JI. Consensus document on the use of antibiotic prophylaxis in dental surgery and procedures. Med Oral Patol Oral Cir Bucal 2006 Mar;11(2):E188-E205.

3. Halling F, Neff A, Heymann P, Ziebart T. Trends in antibiotic prescribing by dental practitioners in Germany. J Craniomaxillofac Surg 2017 Nov;45(11):1854-1859.

4. Robles Raya P, Javierre Miranda AP, Moreno Millán N, Mas Casals A, de Frutos Echániz E, Morató Agustí ML. Management of odontogenic infections in primary care: antibiotic? Aten Primaria 2017 Dec;49(10):611-618.

5. Marsh PD, Martin MV, Lewis MA, Williams DW. Oral microbiology. 5th ed. London: Elsevier Health Sciences; 2009.

6. Samarnayake, L. Essential microbiology for dentistry. 3rd ed. Edinburgh: Churchill Livingstone Elsevier; 2006.

7. Parahitiyawa NB, Scully C, Leung WK, Yam WC, Jin LJ, Samaranayake LP. Exploring the oral bacterial flora: current status and future directions. Oral Dis 2010 Mar;16(2):136-145.

8. Patil S, Rao RS, Sanketh DS, Amrutha N. Microbial flora in oral diseases. J Contemp Dent Pract 2013 Nov;14(6):1202-1208.

9. Takahashi N. Microbial ecosystem in the oral cavity: metabolic diversity in an ecological niche and its relationship with oral diseases. Int Congress Series 2005 Sep;1284:103-112.

10. Shu M, Wong L, Miller JH, Sissons CH. Development of multispecies consortia biofilms of oral bacteria as an enamel and root caries model system. Arch Oral Biol 2000 Jan;45(1):27-40.

11. Gajan EB, Aghazadeh M, Abashov R, Salem Milani A, Moosavi Z. Microbial flora of root canals of pulpally-infected teeth: Enterococcus faecalis a prevalent species. J Dent Res Dent Clin Dent Prospects 2009 Winter;3(1):24-27.

12. Shah HN, Collins DM. Prevotella, a new genus to include Bacteroides melaninogenicus and related species formerly classified in the genus Bacteroides. Int J Syst Bacteriol 1990 Apr;40(2):205-208.

13. Shweta, Prakash SK. Dental abscess: a microbiological review. Dent Res J (Isfahan) 2013 Sep;10(5):585-591.

14. Segura-Egea JJ, Gould K, en BH, Jonasson P,Cotti E, Mazzoni A, Sunay H, Tjäderhane L, Dummer PM. European Society of Endodontology position statement: the use of antibiotics in endodontics. Int Endod J 2018 Jan;51(1):20-25.

15. Bertossi D, Barone A, Iurlaro A, Marconcini S, De Santis D, Finotti M, Procacci P. Odontogenic orofacial infections. J Craniofac Surg 2017 Jan;28(1):197-202.

16. Moghimi M, Baart JA, Karagozoglu KH, Forouzanfar T. Spread of odontogenic infections: a retrospective analysis and review of the literature. Quintessence Int 2013 Apr; 44(4):351-361.

17. Goumas PD, Naxakis SS, Papavasiliou DA, Moschovakis ED, Tsintsos SJ, Skoutelis A. Periapical abscesses: causal bacteria and antibiotic sensitivity. J Chemother 1997 Dec;9(6):415-419.
18. Lewis MA, Parkhurst CL, Douglas CW, Martin MV, Absi EG, Bishop PA, Jones SA. Prevalence of penicillin resistant bacteria in acute suppurative oral infection. J Antimicrob Chemother 1995 Jun;35(6):785-791.

19. Baumgartner JC, Xia T. Antibiotic susceptibility of bacteria associated with endodontic abscesses. J Endod 2003 Jan;29(1):44-47.

20. Isla A, Canut A, Gascón AR, Labora A, Ardanza-Trevijano B, Solinís MA, Pedraz JL. Pharmacokinetic/pharmacodynamic evaluation of antimicrobial treatments of orofacial odontogenic infections. Clin Pharmacokinet 2005 Mar;44(3):305-316.

21. de-Vicente-Rodríguez JC. Maxillofacial cellulitis. Med Oral Patol Oral Cir Bucal 2004;9(Suppl):133-138,126-133.

22. Curtis G. How are odontogenic infections best managed? J Can Dent Assoc 2010 Apr;76:a37.

23. Hupp JR, Ellis E III, Tucker MR. Contemporary oral and maxillofacial surgery. 5th ed. St. Louis (MO): Mosby; 2008.

24. Nóbrega LM, Montagner F, Ribeiro AC, Mayer MA, Gomes BP. Molecular identification of cultivable bacteria from infected root canals associated with acute apical abscess. Braz Dent J 2016 May-Jun;27(3):318-324.

25. Miliro M, Ghali GE, Larsen PE, Waite P, editors. Peterson's principles of oral and maxillofacial surgery. 2nd ed. Hamilton (ON): BC Decker; 2004.

26. Bascones Martínez A, Aguirre Urízar JM, Bermejo Fenoll A, Blanco Carrión A, Gay-Escoda C, González-Moles MA, Gutiérrez Pérez JL, Jiménez Soriano Y, Liébana Ureña J, López Marcos JF, et al. Consensus statement on antimicrobial treatment of odontogenic bacterial infections. Med Oral Patol Oral Cir Bucal 2004 Nov-Dec;9(5):369-376,363-369.

27. Valour F, Sénéchal A, Dupieux C, Karsenty J, Lustig S, Breton P, Gleizal A, Boussel L, Laurent F, Braun E, et al. Actinomycosis: etiology, clinical features, diagnosis, treatment, and management. Infect Drug Resist 2014 Jul;7:183-197.

28. Wong VK, Turmezei TD, Weston VC. Actinomycosis. BMJ 2011 Oct;343:d6099.

29. Mandell G, Bennett J, Dolin R. Mandell, Douglas, and Bennett's principles and practice of infectious diseases. 7th ed. Philadelphia (PA): Churchill Livingstone Elsevier; 2009.

30. Oostman O, Smego RA. Cervicofacial actinomycosis: diagnosis and management. Curr Infect Dis Rep 2005 May;7(3):170-174.

31. Pulverer G, Schütt-Gerowitt H, Schaal KP. Human cervicofacial actinomycoses: microbiological data for 1997 cases. Clin Infect Dis 2003 Aug;37(4):490-497.

32. Moghimi M, Salentijn E, Debets-Ossenkop Y, Karagozoglu KH, Forouzanfar T. Treatment of cervicofacial actinomycosis: a report of 19 cases and review of literature. Med Oral Patol Oral Cir Bucal 2013 Jul;18(4):e627-e632.

33. Birn H. Fibrinolytic activity of alveolar bone in "dry socket". Acta Odontol Scand 1972 Mar;30(1):23-32.

34. Blum IR. Contemporary views on dry socket (alveolar osteitis): a clinical appraisal of standardisation, aetiopathogenesis and management: a critical review. Int J Oral Maxillofac Surg 2002 Jun;31(3):309-317.

35. Bowe DC, Rogers S, Stassen LF. The management of dry socket/alveolar osteitis. J Ir Dent Assoc 2011Dec;57(6):305-310.

36. Cardoso CL, Rodrigues MT, Ferreira Júnior O, Garlet GP, de Carvalho PS. Clinical concepts of dry socket. J Oral Maxillofac Surg 2010 Aug;68(8):1922-1932.

37. Gaetti-Jardim E Jr, Ciesielski FI, Possagno R, de Castro AL, Marqueti AC, Gaetti-Jardim EC. Chronic osteomyelitis of the maxilla and mandible: microbiological and clinical aspects. Int J Odontostomat 2010;4(2):197-202. 
38. Gaetti-Jardim E Jr, Fardin AC, Gaetti-Jardim EC, de Castro AL, Schweitzer CMA, Campos MJ. Microbiota associated with chronic osteomyelitis of the jaws. Braz J Microbiol 2010 Oct;41(4):1056-1064.

39. Mandal R, Patel N, Ferguson BJ. Role of antibiotics in sinusitis. Curr Opin Infect Dis 2012 Apr;25(2):183-192.

40. Workman AD, Granquist EJ, Adappa ND. Odontogenic sinusitis: developments in diagnosis, microbiology, and treatment. Curr Opin Otolaryngol Head Neck Surg 2018 Feb;26(1):27-33.

41. Vidal F, Coutinho TM, Carvalho Ferreira D, Souza RC, Gonçalves LS. Odontogenic sinusitis: a comprehensive review. Acta Odontol Scand 2017 Nov;75(8):623-633.

42. PuglisiS, PriviteraS, Maiolino L, Serra A, Garotta M, BlandinoG, Speciale A. Bacteriological findings and antimicrobial resistance in odontogenic and non-odontogenic chronic maxillary sinusitis. J Med Microbiol 2011 Sep;60(Pt 9):1353-1359.
43. Zhang X, Sun Z, Yang Q. Application of Denaturing gradient gel electrophoresis to the analysis of bacterial communities associated with asymptomatic and symptomatic pericoronitis. J Oral Maxillofac Surg 2018 Mar;76(3):483-489.

44. Suárez-López Del Amo F, Yu SH, Wang HL. Non-surgical therapy for peri-implant diseases: a systematic review. J Oral Maxillofac Res 2016 Sep;7(3):e13.

45. Aberg CH, Kelk P, Johansson A. Aggregatibacter actinomycetemcomitans: virulence of its leukotoxin and association with aggressive periodontitis. Virulence 2015 Apr;6(3):188-195.

46. Larsen OI, Enersen M, Kristoffersen AK, Wennerberg A, Bunæs DF, Lie SA, Leknes KN. Antimicrobial effects of three different treatment modalities on dental implant surfaces. J Oral Implantol 2017 Dec;43(6):429-436.

47. Prathapachandran J, Suresh N. Management of periimplantitis. Dent Res J (Isfahan) 2012 Sep-Oct;9(5):516-521. 